\title{
Measurement of Acid Ecto-phosphatase Activity in Live Leishmania donovani Parasites
}

\author{
Amalia Papadaki ${ }^{1, \$}$ and Haralabia Boleti ${ }^{1,2, *}$
}

\begin{abstract}
${ }^{1}$ Intracellular Parasitism Laboratory, Microbiology Department, Hellenic Pasteur Institute, Athens 11521, GREECE; '2Light Microscopy Unit, Hellenic Pasteur Institute, Athens 11521, GREECE; \$Current address: EOF, National Organization for Medicines, Veterinary Medicines Assessment Section, 15562 Cholargos, GREECE
\end{abstract}

*For correspondence: hboleti@pasteur.gr

[Abstract] Acid ecto-phosphatases are enzymes that hydrolyze phosphomonoesters in the acidic $\mathrm{pH}$ range with their active sites facing the extacellular medium. Their activities can be measured in living cells. In bacteria and protozoan pathogens, acid ecto-phosphatases have been associated with the survival of intracellular pathogens within phagocytes through inhibition of the respiratory burst, suggesting that they act as virulence factors. Extracellular acid phosphatase activity in Leishmania (L.) donovani has been associated with the degree of promastigote virulence/infectivity. The levels of acid ecto-phosphatase activity in different Leishmania sp or even strains of the same species vary and this has been linked to their virulence. It may also be related to their ability to survive and multiply in the insect host.

Acid phosphatase enzymatic activity can be measured in crude membrane fractions and in membrane fractions enriched in plasma membrane, however, in these cases, the intracellular acid phosphatases, mainly localized in lysosomes, contribute to the final result. Therefore, measuring phosphatase activity at the surface of live cells in acidic $\mathrm{pH}$ range is the only accurate way to measure acid ecto-phosphatase activity. This assay is performed at $25^{\circ} \mathrm{C}$ or $37^{\circ} \mathrm{C}$ for $30 \mathrm{~min}$ using as substrate the generic phosphatase substrate -nitrophenyl phosphate ( $p N P P)$, in a citrate buffer, with or without sodium tartrate $(L(+)-$ tartaric acid), as histidine acid phosphatases are classified according to their sensitivity to tartate inhibition. The steps of the protocol consist of pelleting cells in suspension, in this case Leishmania promastigotes, washing twice with HEPES buffer, resuspending the cells in the substrate reaction mixture and terminating the reaction by the addition of $0.5 \mathrm{~N} \mathrm{NaOH}$. The cells are removed by centrifugation and the absorbance of the reaction product ( $p$-nitrophenolate $=p N P)$ in the supernatant is measured at $405 \mathrm{~nm}$. The enzymatic activity ( $\mathrm{A}_{405}$ values) is normalized for the mean number of cells $/ \mathrm{ml}$ used for each independent experiment.

Keywords: Ecto-enzymes, Acid ecto-phosphatases, Enzymatic assay in live cells, Leishmania sp, phosphatase activity, Tartate sensitivity

[Background] Trypanosomatid protozoan parasites are a diverse group of primitive parasitic organisms (Kaufer et al., 2017). They are both of medical and veterinary importance as many Trypanosomatid species cause serious or fatal diseases in humans and agricultural animals in tropical and subtropical regions worldwide (Reference 16). Virulence factors of these parasites include molecules expressed on 
their cell surface as well as those secreted or shed into the extracellular medium (Gottlieb and Dwyer, 1981; Fonseca-de-Souza et al., 2008 and 2009). Trypanosomatidae are exposed to diverse environmental stimuli throughout their life cycles in all biological systems they reside. Central events in recognition of the external and internal signals in these cells, which lead to specific responses for adaptation and survival in all these environments, are protein phosphorylation and dephosphorylation events carried out by a multitude of kinases and phosphatases. The trypanosomatid kinome and phosphatome have been recently deciphered (Brenchley et al., 2007; Sadatomi et al., 2013).

Phosphatase activities modulate different aspects of the infection by members of the trypanosomatid family (Neves et al., 2014). Ecto-phosphatases, the enzymes localized in parasite's surface membranes, are of special interest as they are candidate molecules for the interaction between the parasite and its host and thereby they could be intimately involved in many cellular events implicated in parasite adhesion to the host, protection from the host's immune response and establishment of infection. Moreover, several alternative functions have been suggested for ecto-phosphatases, such as participation in proliferation, differentiation, adhesion, virulence and infection (Katakura and Kobayashi, 1988; Singla et al., 1992). Little is known about their physiological roles in protozoa parasites (Cosentino-Gomes et al., 2011; Gomes et al., 2011). In particular, acid ecto-phosphatases that hydrolyze phosphomonoesters at acidic pHs, have been associated with the survival of intracellular parasites within phagocytes through inhibition of the respiratory burst (Saha et al., 1985; Remaley et al., 1985; Baca et al., 1993; Reilly et al., 1996; Jungnitz et al., 1998; Saleh and Belisle, 2000; Burtnick et al., 2001; Steenkamp, 2002; Cosentino-Gomes et al., 2009; Aragon et al., 2011; Cosentino-Gomes and MeyerFernandes, 2011), suggesting that they may act as virulence factors (Katakura and Kobayashi, 1988; Singla et al., 1992; Papadaki et al., 2015). They may also be related to the ability of parasites to survive and multiply in the insect host (Remaley et al., 1985; Saha et al., 1985; Singla et al., 1992). The field of the acid ecto-phosphatases was reopened with the characterization of the $L$. donovani acid ectophosphatase LdMAcP (Papadaki et al., 2015) and the identification of at least two more open reading frames in the $L$. donovani genome that could be potentially expressed at the surface membrane of the parasites (Papadaki and Boleti. data not published).

Therefore assaying acid phosphate activity at the surface of live cells is a putative diagnostic parameter for virulence of Leishmania parasite strains as well as for the evaluation of the expression of the ecto-phosphatases under study at the surface of transgenic parasite strains overexpressing them. Acid phosphatase enzymatic activity can be measured in crude membrane fractions and in membrane fractions enriched in plasma membrane (Glew et al., 1982; Shakarian et al., 2002), however, in these cases, the intracellular acid phosphatases, mainly localized in lysosomes, contribute to the final result.

The protocol provided herein was used to measure acid ecto-phosphatase activity in live Leishmania promastigotes but it could be used to detect and quantitate acid ecto-phosphatase activity in all suspension cells of prokaryotic or eukaryotic origin.

Our method was adapted from previously described methodologies (Remaley et al., 1985; Saha et al., 1985; Katakura and Kobayashi, 1988; Singla et al., 1992) for assaying ecto-phosphatases in other organisms. 


\section{Materials and Reagents}

1. Plastic cuvettes for spectrophotometric analysis (i.e., Sigma-Aldrich, catalog number: C5677)

2. Plastic flasks for parasite culture 25 and $50 \mathrm{~cm}^{2}$

3. Plastic pipette tips (for $20 \mu \mathrm{l}, 200 \mu \mathrm{l}$ and $1 \mathrm{ml}$ pipettes)

4. Sterile plastic pipettes $(1 \mathrm{ml}, 2 \mathrm{ml}, 5 \mathrm{ml}$ and $10 \mathrm{ml}$, from any company)

5. Falcon plastic tubes 15 and $50 \mathrm{ml}$ (from any company)

6. Plastic Eppendorf tubes $1.5 \mathrm{ml}$ (from any company)

7. Gilson or Eppendorf pipettes (or from any other company) for $1 \mu \mathrm{l}, 20 \mu \mathrm{l}, 200 \mu \mathrm{l}$ and $1 \mathrm{ml}$ volumes

8. L. tarentolae promastigotes (LEXSY host P10, Jena Biosciences, catalog number: LT-101)

9. pLEXSY-sat2 vector (Jena Biosciences, catalog number: EGE-274)

10. Brain Heart Infusion (Lexsy Broth BHI, Jena Biosciences, catalog number: ML-412S), stored at $4{ }^{\circ} \mathrm{C}$ when diluted in sterile $\mathrm{dH}_{2} \mathrm{O}$

11. Hemin (Jena Biosciences, catalog number: ML-108L), stored at RT

12. L-biopterin (Cayman, catalog number: 10007662 ), stored at $-20^{\circ} \mathrm{C}$

13. Nourseothricin (LEXSY NTC, Jena Bioscience, catalog number: AB-102L). Prepare solution of $10 \mathrm{mg} / \mathrm{ml}$ with sterile $\mathrm{dH}_{2} \mathrm{O}$, store in aliquots of $100 \mu \mathrm{l}$ at $-20^{\circ} \mathrm{C}$ and after thawing at $4{ }^{\circ} \mathrm{C}$

14. RPMI 1640-GlutaMax (Thermo Fisher, catalog number: $61870-010$ ), stored at $4{ }^{\circ} \mathrm{C}$

15. Schneider's (Sigma-Aldrich, catalog number: S-9895), stored at $4{ }^{\circ} \mathrm{C}$

16. hiFBS: FBS (From Gibco, Thermo Fisher, Biosera or any other company tested), stored at -20 ${ }^{\circ} \mathrm{C}$, inactivated at $56{ }^{\circ} \mathrm{C}$ for $30 \mathrm{~min}$ before added to the culture medium

17. Penicillin-Streptomycin $10,000 \mathrm{U} / \mathrm{ml}$ (100x concentrated, Thermo Scientific, catalog number: 15140-122 or from any other company tested), stored at $-20{ }^{\circ} \mathrm{C}$

18. HEPES $1 \mathrm{M}$ (Thermo Fisher Scientific, catalog number: 15630080), stored at $4{ }^{\circ} \mathrm{C}$

19. 4-Nitrophenyl phosphate disodium salt hexahydrate, pNPP (Sigma-Aldrich, catalog number: P4744), powder stored at $-20^{\circ} \mathrm{C}$. Prepare solution of $10 \mathrm{mM}$ fresh for each experiment

20. $90 \mathrm{mM}$ citrate buffer at $\mathrm{pH} 4.8\left(25^{\circ} \mathrm{C}\right)$ (Sigma-Aldrich, catalog number: $\left.\mathrm{C} 2488\right)$, stored at 2-8 ${ }^{\circ} \mathrm{C}$

21. $\mathrm{NaOH} 0.5 \mathrm{M}$ solution (Applichem, catalog number: 181692.1211), stored at RT

22. Sodium tartrate $(5 \mathrm{mM})$ solution; $\mathrm{L}(+)$-tartaric acid (Merck, catalog number: 100804 , or SigmaAldrich, catalog number: T109), stored at RT

23. $0.4 \%(w / v)$ Trypan Blue solution (Gibco, catalog number: 15250061; or Sigma-Aldrich, catalog number: T8154)

24. Formalin $100 \%$ (37\% w/v formaldehyde solution; MERC: catalog number F8775 or from any other comany) 


\section{Equipment}

1. Hemocytometer (Malassez, Marienfeld, catalog number: 0640610)

2. Incubator operating at $25{ }^{\circ} \mathrm{C}$ for the maintenance of parasite cultures (for example Shel-lab microbiological or $\mathrm{CO}_{2}$ incubator, https://www.sheldonmanufacturing.com/shel-lab-incubators or from any other company)

3. Water bath (i.e., ED13, Julabo)

4. Analytical balance (i.e., AE50, Mettler)

5. Spectrophotometer (i.e., SmartSpec Plus Spectrophotometer, 170-2525, Bio-Rad)

6. Tabletop centrifuge (i.e., Jouan CR3i multifunction, Thermo)

7. Microcentrifuge (i.e., Eppendorf 5417R)

\section{Software}

1. GraphPad Prism Software 5.01 (GraphPad, San Diego, CA)

\section{Procedure}

A. Leishmania promastigote axenic culture

1. L. donovani, L. major or L. infantum promastigotes grow as suspension cells in axenic (in vitro cultures).

2. When starting from a frozen vial, thaw the cells quickly by immersing the vial in a beaker with water at $25{ }^{\circ} \mathrm{C}$, transfer with a sterile $1 \mathrm{ml}$ pippete in a falcon tube with $9 \mathrm{ml}$ culture medium[RPMI 1640-GlutaMax, supplemented with 10\% (v/v) hiFBS, 40 mM HEPES and antibiotics (penicillin-streptomycin at $1 \mathrm{x}$ dilution $(100 \mathrm{U} / \mathrm{ml})$ ], resuspend and centrifuge at $1000 \times \mathrm{g}$ for 7 min at RT.

3. Remove the $\mathrm{S} / \mathrm{N}$, resuspend in $10 \mathrm{ml}$ culture medium and transfer into a $25 \mathrm{~cm}^{2}$ flask, close cap (without filter).

4. Culture at $25^{\circ} \mathrm{C}$ in the absence of $\mathrm{CO}_{2}$ as described previously (Papadaki et al., 2015).

5. Parasite subculturing is performed at $10^{6}$ parasites $/ \mathrm{ml}$ and at the $6^{\text {th }}-7^{\text {th }}$ day of culture the parasite density is $\sim 2 \times 10^{7}-2.5 \times 10^{7}$ parasites $/ \mathrm{ml}$.

6. Parasite harvesting is performed by centrifugation ( $1,000 \times \mathrm{g}, 7 \mathrm{~min}$ at RT).

7. Parasites can be cultured for up to 10 passages and then a new culture should be started from a vial with frozen cells.

8. Culture L. tarentolae promastigotes at $25{ }^{\circ} \mathrm{C}$ in Brain Heart Infusion (Lexsy Broth $\mathrm{BHI}$ ) medium supplemented with hemin $(5 \mu \mathrm{g} / \mathrm{ml})$ at a final concentration of $0.25 \%(\mathrm{w} / \mathrm{v}), 10 \mu \mathrm{M} \mathrm{L-biopterin}$ and penicillin-streptomycin (1x). 
9. Genetically modified parasites are cultured in similar conditions with the parental strains but with addition of Nourseothricin $(100 \mu \mathrm{g} / \mathrm{ml})$ when the genetic modification was performed with plasmids based on the pLEXSY-sat2 vector.

10. For parasite maintenance, $L$. donovani strains $\left(10^{7}\right.$ cells $)$ are subcultured once a week by removing $9 \mathrm{ml}$ of the old culture and complementing with $9 \mathrm{ml}$ of fresh medium (1/10 dilution).

11. For cell counting

a. Remove a small volume of the culture $(100 \mu \mathrm{l})$ for counting the cells with a hemocytometer (Malassez) and transfer it into an Eppendorf tube containing $900 \mu \mathrm{l} \%$ (w/v) formalin, at RT.

b. Wait for 2-3 min.

c. Take $100 \mu \mathrm{l}$ and place in one chamber of the hemocytometer.

Note: For use of hemocytometer, you can look at videos like https://www.youtube.co $\underline{m} /$ watch? $=W W S 9 s Z b G j 6 A$.

d. Observe under the microscope with a 40x magnification lens.

e. For counting cells in the Mallassez hemocytometer, see image (Figure 1), below for a representation of the mallassez chamber.
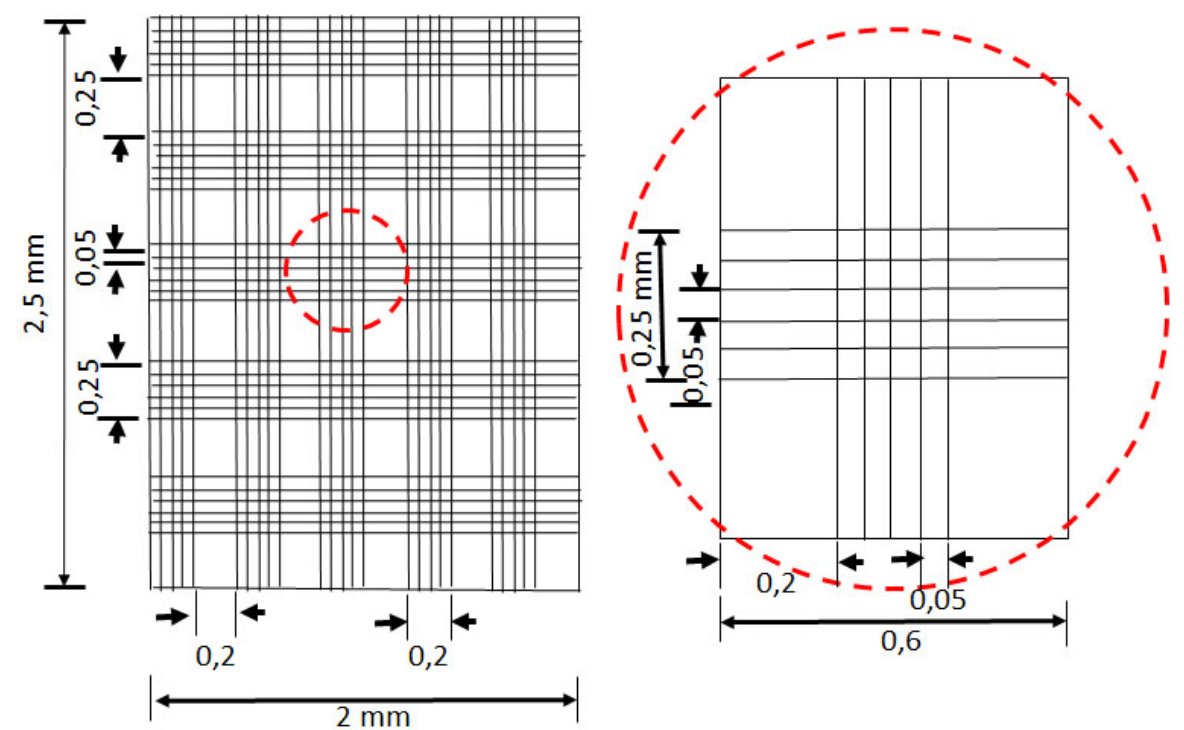

Figure 1. Graphical representation of the Mallassez hemocytometer chamber. Count the cells in several or in all the large squares (each square has an area of $0.05 \mathrm{~mm}^{2}$ and $0.2 \mathrm{~mm}$ depth representing a volume of $0.01 \mathrm{~mm}^{3}=10^{-5} \mathrm{ml}$ ). Divide the number of cells counted by the number of squares observed and multiply by $105 / \mathrm{ml}$. Then multiply with the dilution factor (in this case by 10). If the parasite culture is less dense, dilute in a smaller volume of formalin before counting.

B. Protocol of assaying acid ecto-phosphatase in live Leishmania promastigotes 
The acid ecto-phosphatase activity at the surface of live Leishmania promastigotes, is assayed at $25^{\circ} \mathrm{C}$ or $37^{\circ} \mathrm{C}$ for 30 min with the phosphatase substrate $p$-nitrophenyl phosphate ( $p$ NPP) $(10 \mathrm{mM})$ in a $90 \mathrm{mM}$ citrate buffer at $\mathrm{pH} 4.8$ (Sigma-Aldrich), with or without sodium tartrate $(5 \mathrm{mM}, \mathrm{L}(+)$ tartaric acid; Merck). Hydrolysis of the esteric bond and dephosphorylation of $p$ NPP produces the p-nitro-phenol compound which after terminating the reaction by the addition of $0.5 \mathrm{~N} \mathrm{NaOH}$ is quantified by measuring its absorbance at $405 \mathrm{~nm}$ (Figure 2).

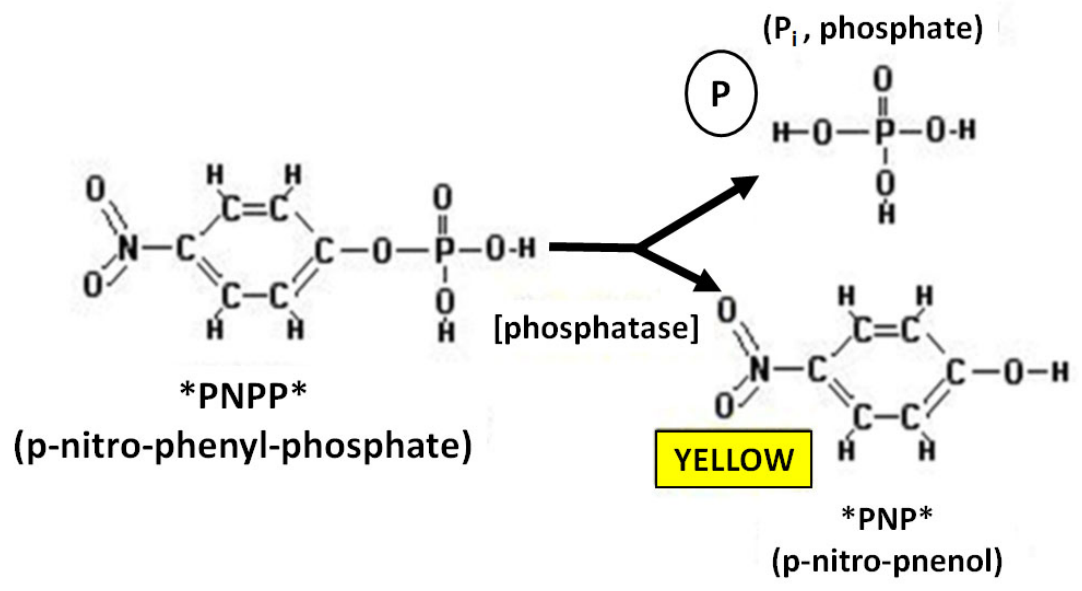

Figure 2. Diagram of the enzymatic reaction of dephosphorylation of the pNPP substrate.

The acid ecto-phosphatase reaction at the surface of live Leishmania promastigotes can be carried out either at the logarithmic phase of growth (48-72 $\mathrm{h}$ post inoculation of the culture) or at the static phase of growth ( $6^{\text {th }}$ or $7^{\text {th }}$ day post-inoculation).

1. Harvest Leishmania promastigotes $\left(1-2 \times 10^{7}\right)$ by centrifugation $(1,000 \times g, 7 \mathrm{~min}, \mathrm{RT})$.

2. Resuspend the cell pellet with $5 \mathrm{ml} 100 \mathrm{mM}$ HEPES solution and wash twice with the same buffer.

3. Count cells (as in step 11, A) and assess cell viability by visual inspection under the microscope of the parasite motility (dispense $50 \mu \mathrm{l}$ of cell suspension on a microscope slide and observe with a $4 \mathrm{x}$ lens) and quantitation by staining with $0.4 \%$ (w/v) Trypan Blue (i.e., as in Trypan Blue Staining protocol). Counting and cell viability could be performed simultaneously.

4. Centrifuge the large volume of the cell suspension $(1,000 \times \mathrm{g}, 7 \mathrm{~min})$.

5. Discard the supernatant $(\mathrm{S} / \mathrm{N})$.

6. Resuspend the cell pellet in $500 \mu \mathrm{l}$ reaction solution containing the phosphatase substrate $\mathrm{p}$ nitrophenyl phosphate (10 mM pNPP in a $90 \mathrm{mM}$ citrate buffer, $\mathrm{pH} 4.8$ ), with or without sodium tartrate $5 \mathrm{mM} \mathrm{L}(+)$-tartaric acid prewarmed in the appropriate temperature of the reaction $(25$ ${ }^{\circ} \mathrm{C}$ or at $37^{\circ} \mathrm{C}$ ).

7. Incubate cells in the reaction mixture at $25^{\circ} \mathrm{C}$ or $37^{\circ} \mathrm{C}$ for $30 \mathrm{~min}$.

8. Terminate the reaction by the addition of $0.5 \mathrm{~N} \mathrm{NaOH}(1 \mathrm{ml} /$ sample).

9. Remove the parasites by centrifugation $(2,000 \times \mathrm{g}, 5 \mathrm{~min})$.

10. Transfer the $S / N$ in a plastic cuvette for spectrophotometric analysis.

11. Measure the absorbance of the reaction product ( $p$-nitrophenolate $=p N P)$ at $405 \mathrm{~nm}$. 
12. Calculate the enzyme activity ( $A_{405}$ values) and normalize for the mean number of cells $/ \mathrm{ml}$ for each independent experiment $\left(\mathrm{A}_{405} / 10^{7} \mathrm{cells} / \mathrm{ml}\right)$.

13. Evaluate the acid phosphatase activity due to cell lysis under the reaction conditions as follows:

a. Incubate reaction buffer, equal volume to the phosphatase assay for each cell type, with the same number of Leishmania promastigotes used for each reaction, in the absence of substrate for $30 \mathrm{~min}$, at $25^{\circ} \mathrm{C}$ or $37^{\circ} \mathrm{C}$ depending on the temperature you are performing the reaction.

b. Recover the $\mathrm{S} / \mathrm{N}$ after centrifuging down the cells $(2,000 \times \mathrm{g}, 5 \mathrm{~min})$.

c. Add $10 \mathrm{mM} p \mathrm{NPP}$.

d. Incubate for $30 \mathrm{~min}$.

e. Measure acid phosphatase activity as described above.

14. Access cell viability as described in Step B2.

\section{Data analysis}

The acid phosphatase activity could be presented in a graph format (Figure 3 ) or a table (Table 1). Graphs and statistical significance were prepared and analyzed using GraphPad Prism Software 5.01 (GraphPad, San Diego, CA). The paired Student's $t$-test was used to evaluate statistical significance among groups. A $P$ value $<0.05$ was considered statistically significant.

A

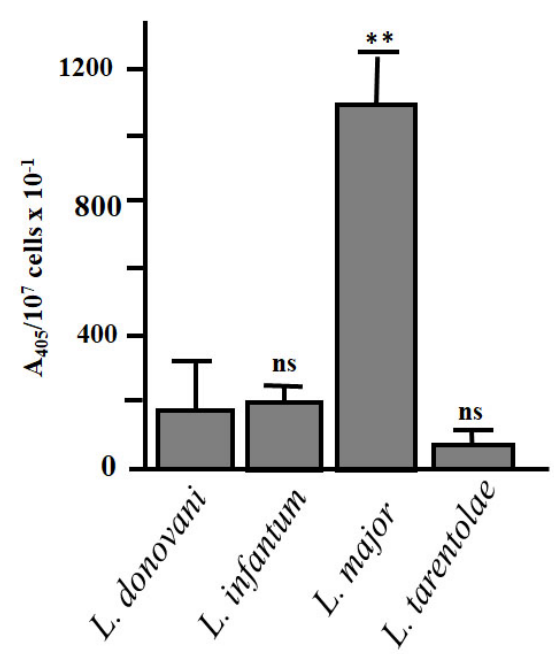

B + tartate

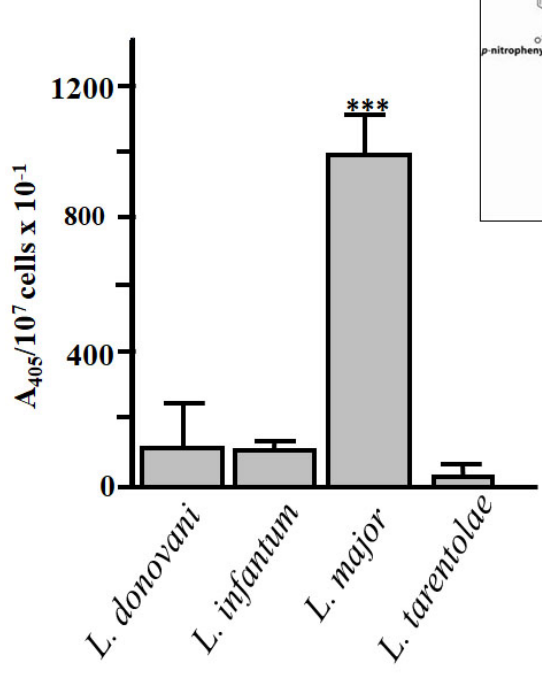

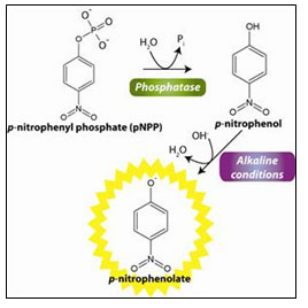

Figure 3. Graphical representation of the results of acid ecto-phosphatase assay in live promastigotes of four different Leishmania sp (L. donovani strain LG13, L. infantum strain GH12, L. major strain Friedlin, $L$. tarentolae strain LEXSY). The phosphatase activity was estimated in the presence of $5 \mathrm{mM}$ sodium tartate (+ tartate) or in the absence of the inhibitor. Values are normalized to the $\%$ of live cells. A. The assay was performed without sodium tartate. B. $5 \mathrm{mM}$ Sodium tartate was added to the assay mixture. The L. major-Friedlin 
strain had dramatically higher activity, $\sim 7-8$ fold, than the L. infantum-GH1 and L. donovaniLG13 strains, respectively, and this activity was $>90 \%$ sodium tartrate resistant. Error bars are Stds from 3 independent experiments. ${ }^{* *},{ }^{* * *} P \leq 0.01 \& \leq 0.001$ respectively, compared with corresponding control values (L. donovani-LG13), using a two-tailed paired Student's $t$-test. ns: not significant.

Table 1. Acid ecto-phopshatase activity in live Leishmania spp promastigotes of the static phase of growth. Results are means from 3 independent experiments \pm STD values *, ${ }^{* *} P \leq 0.05 \& 0.01$, respectively, statistically significant differences as compared with control values (L. donovani strain LG13), two-tailed paired Student's $t$-test. (Papadaki Amalia, PhD thesis 2015, https://www.didaktorika.gr/eadd/handle/10442/39638). Values are normalized to the $\%$ of live cells.

\begin{tabular}{lll}
\hline \multicolumn{1}{c}{ Leishmania strains } & \multicolumn{1}{c}{$\begin{array}{c}\text { Acid ecto-phosphatase activity } \\
\left(\mathrm{A}_{\left.405 / 10^{7} \text { cells } \times \mathrm{ml}^{-1}\right)}\right.\end{array}$} \\
\hline & - tartate & $+5 \mathrm{mM}$ tartate \\
L. donovani (LG13 strain) & $142 \pm 57$ & $63 \pm 26$ \\
L. infantum (GH12 strain) & $168 \pm 49$ & $88 \pm 16$ \\
L. major (Friedlin strain) & $1113 \pm 188^{* *}$ & $925 \pm 87^{* *}$ \\
L. tarentolae (Lexsy strain) & $46 \pm 26^{*}$ & $27 \pm 14^{*}$ \\
\hline
\end{tabular}

\section{Notes}

1. Viability of the cells should be assessed before and after incubation with the reaction medium qualitatively by visual inspection under the microscope of the parasite motility and quantitatively by $0.4 \%$ (w/v) Trypan Blue staining or by staining with another vital dye, as described in the protocol.

2. Additionally, it should be confirmed that the enzymatic activity measured in the assay with live cells is due to acid ecto-phosphatase(s) and not to released enzymes by a) incubating the same number of parasites used in the assay with the reaction medium at $37^{\circ} \mathrm{C}$ for $30 \mathrm{~min}, \mathrm{~b}$ ) removing the parasites by centrifugation and c) testing for pNPP hydrolysis in this medium devoid of cells (Cedro Fernandes et al., 2003).

\section{Acknowledgments}

This work was funded by the Hellenic Pasteur Institute (http://www.pasteur.gr) AP and HB, a sponsorship from Genesis Pharma S.A (http://www.genesispharma.gr/homeeng.htm) HB, and a Bilateral Research \& Technology Collaboration Greece-France 2013 grant (No. 1811) funded by the Greek General Secretariat for Research and Technology (http://www.gsrt.gr/central.aspx?sld=119|428|1089|323/488743) AP and HB. 


\section{Competing interests}

The authors have no financial or non-financial competing interests on the information provided in this manuscript.

\section{References}

1. Aragon, V., Kurtz, S. and Cianciotto, N. P. (2001). Legionella pneumophila major acid phosphatase and its role in intracellular infection. Infect Immun 69(1): 177-185.

2. Baca, O. G., Roman, M. J., Glew, R. H., Christner, R. F., Buhler, J. E. and Aragon, A. S. (1993). Acid phosphatase activity in Coxiella burnetii: a possible virulence factor. Infect Immun 61(10): 4232-4239.

3. Brenchley, R., Tariq, H., McElhinney, H., Szoor, B., Huxley-Jones, J., Stevens, R., Matthews, K. and Tabernero, L. (2007). The TriTryp phosphatome: analysis of the protein phosphatase catalytic domains. BMC Genomics 8: 434.

4. Burtnick, M., Bolton, A., Brett, P., Watanabe, D. and Woods, D. (2001). Identification of the acid phosphatase (acpA) gene homologues in pathogenic and non-pathogenic Burkholderia spp. facilitates TnphoA mutagenesis. Microbiology 147(Pt 1): 111-120.

5. Cedro Fernandes, E., Mauro Granjeiro, J., Mikio Taga, E., Meyer-Fernandes, J. R. and Aoyama, H. (2003). Phosphatase activity characterization on the surface of intact bloodstream forms of Trypanosoma brucei. FEMS Microbiol Lett 220(2): 197-206.

6. Cosentino-Gomes, D. and Meyer-Fernandes, J. R. (2011). Ecto-phosphatases in protozoan parasites: possible roles in nutrition, growth and ROS sensing. J Bioenerg Biomembr 43(1): 8992.

7. Cosentino-Gomes, D., Russo-Abrahao, T., Fonseca-de-Souza, A. L., Ferreira, C. R., Galina, A. and Meyer-Fernandes, J. R. (2009). Modulation of Trypanosoma rangeli ecto-phosphatase activity by hydrogen peroxide. Free Radic Biol Med 47(2): 152-158.

8. Fonseca-de-Souza, A. L., Dick, C. F., Dos Santos, A. L. and Meyer-Fernandes, J. R. (2008). A $\mathrm{Mg}^{2+}$-dependent ecto-phosphatase activity on the external surface of Trypanosoma rangeli modulated by exogenous inorganic phosphate. Acta Trop 107(2): 153-158.

9. Fonseca-de-Souza, A. L., Dick, C. F., dos Santos, A. L., Fonseca, F. V. and Meyer-Fernandes, J. R. (2009). Trypanosoma rangeli: a possible role for ecto-phosphatase activity on cell proliferation. Exp Parasitol 122(3): 242-246.

10. Glew, R. H., Czuczman, M. S., Diven, W. F., Berens, R. L., Pope, M. T. and Katsoulis, D. E. (1982). Partial purification and characterization of particulate acid phosphatase of Leishmania donovani promastigotes. Comp Biochem Physiol B 72(4): 581-590.

11. Gomes, M. T., Lopes, A. H. and Meyer-Fernandes, J. R. (2011). Possible roles of ectophosphatases in host-parasite interactions. J Parasitol Res 2011: 479146.

12. Gottlieb, M. and Dwyer, D. M. (1981). Protozoan parasite of humans: surface membrane with 
externally disposed acid phosphatase. Science 212(4497): 939-941.

13. Jungnitz, H., West, N. P., Walker, M. J., Chhatwal, G. S. and Guzman, C. A. (1998). A second two-component regulatory system of Bordetella bronchiseptica required for bacterial resistance to oxidative stress, production of acid phosphatase, and in vivo persistence. Infect Immun 66(10): 4640-4650.

14. Katakura, K. and Kobayashi, A. (1988). Acid phosphatase activity of virulent and avirulent clones of Leishmania donovani promastigotes. Infect Immun 56(11): 2856-2860.

15. Kaufer, A., Ellis, J., Stark, D. and Barratt, J. (2017). The evolution of trypanosomatid taxonomy. Parasit Vectors 10(1): 287.

16. Neglected tropical diseases [Internet]. 2018 [cited July 2018]. Available from: http://www.who.int/neglected diseases/diseases/en/.

17. Neves, R. F., Fernandes, A. C., Meyer-Fernandes, J. R. and Souto-Padron, T. (2014). Trypanosoma cruzi-secreted vesicles have acid and alkaline phosphatase activities capable of increasing parasite adhesion and infection. Parasitol Res 113(8): 2961-2972.

18. Papadaki, A., Politou, A. S., Smirlis, D., Kotini, M. P., Kourou, K., Papamarcaki, T. and Boleti, H. (2015). The Leishmania donovani histidine acid ecto-phosphatase LdMAcP: insight into its structure and function. Biochem J 467(3): 473-486.

19. Reilly, T. J., Baron, G. S., Nano, F. E. and Kuhlenschmidt, M. S. (1996). Characterization and sequencing of a respiratory burst-inhibiting acid phosphatase from Francisella tularensis. J Biol Chem 271(18): 10973-10983.

20. Remaley, A. T., Glew, R. H., Kuhns, D. B., Basford, R. E., Waggoner, A. S., Ernst, L. A. and Pope, M. (1985). Leishmania donovani: surface membrane acid phosphatase blocks neutrophil oxidative metabolite production. Exp Parasitol 60(3): 331-341.

21. Sadatomi, D., Tanimura, S., Ozaki, K. and Takeda, K. (2013). Atypical protein phosphatases: emerging players in cellular signaling. Int J Mol Sci 14(3): 4596-4612.

22. Saha, A. K., Das, S., Glew, R. H. and Gottlieb, M. (1985). Resistance of leishmanial phosphatases to inactivation by oxygen metabolites. J Clin Microbiol 22(3): 329-332.

23. Saleh, M. T. and Belisle, J. T. (2000). Secretion of an acid phosphatase (SapM) by Mycobacterium tuberculosis that is similar to eukaryotic acid phosphatases. $J$ Bacteriol 182(23): 6850-6853.

24. Shakarian, A. M., Joshi, M. B., Ghedin, E. and Dwyer, D. M. (2002). Molecular dissection of the functional domains of a unique, tartrate-resistant, surface membrane acid phosphatase in the primitive human pathogen Leishmania donovani. J Biol Chem 277(20): 17994-18001.

25. Singla, N., Khuller, G. K. and Vinayak, V. K. (1992). Acid phosphatase activity of promastigotes of Leishmania donovani: a marker of virulence. FEMS Microbiol Lett 73(3): 221-225.

26. Steenkamp, D. J. (2002). Trypanosomal antioxidants and emerging aspects of redox regulation in the trypanosomatids. Antioxid Redox Signal 4(1): 105-121. 